\title{
Significance of neoadjuvant chemoradiotherapy for borderline resectable pancreatic head cancer: Pathological local invasion and microvessel invasion analysis
}

\author{
YOSHIKI NAITO ${ }^{1,2^{*}}$, HIROTO ISHIKAWA ${ }^{3 *}$, EIJI SADASHIMA ${ }^{4 *}$, YOSHINOBU OKABE $^{5}$, \\ KENJIRO TAKAHASHI $^{3}$, RYUICHI KAWAHARA ${ }^{3}$, TORU HISAKA ${ }^{3}$, MASARU FUKAHORI $^{5}$, \\ TOMOYUKI USHIJIMA $^{5}$, YUSUKE ISHIDA ${ }^{5}$, MASAHIKO TANIGAWA ${ }^{2}$, YUTARO MIHARA ${ }^{2}$, \\ MASAMICHI NAKAYAMA $^{2}$, REIICHIRO KONDO ${ }^{2}$, HIRONORI KUSANO $^{2}$, YORIHIKO TAKASE ${ }^{1}$, \\ HIDEYUKI ABE ${ }^{1}$, ETSUYO OGO ${ }^{6}$, KOJI OKUDA ${ }^{3}$, KAZUHIDE SHIMAMATSU $^{7}$, \\ HIROHISA YANO ${ }^{2}$ and JUN AKIBA ${ }^{1}$
}

\author{
${ }^{1}$ Department of Diagnostic Pathology, Kurume University Hospital; Departments of ${ }^{2}$ Pathology and ${ }^{3}$ Surgery, \\ Kurume University School of Medicine, Kurume, Fukuoka 830-0011; ${ }^{4}$ Life Science Research Institute, Saga-ken Medical \\ Center Koseikan, Saga 840-8571; ${ }^{5}$ Division of Gastroenterology, Department of Medicine, Kurume University \\ School of Medicine; ${ }^{6}$ Department of Radiology, Kurume University School of Medicine, Kurume, \\ Fukuoka 830-0011; ${ }^{7}$ Department of Pathology, Omuta City Hospital, Omuta, Fukuoka 836-8567, Japan
}

Received December 24, 2018; Accepted May 9, 2019

DOI: $10.3892 / \operatorname{mco} .2019 .1885$

\begin{abstract}
Borderline resectable pancreatic head cancer (BR-PHC) has low resectability due to vascular invasion. Although the clinical effects of neoadjuvant chemoradiotherapy (NAC-RT) for BR-PHC have been examined, few studies have reported its pathological aspects. The present study retrospectively investigated the effect of NAC-RT on the histological features of BR-PHC. A total of 29 patients with BR-PHC who underwent NAC-RT, and 55 controls with resectable PHC, who underwent pancreaticoduodenectomy at the Kurume University Hospital. Tumor staging, lymphovascular invasion (LVI), and microvessel invasion (MVI) were evaluated. The median tumor size in the NAC-RT group was $2.0 \mathrm{~cm}$, and it was smaller than that of the control group $(\mathrm{P}=0.006)$. The rates of lymph node metastasis, LVI, and MVI were significantly lower in the NAC-RT group $(\mathrm{P}<0.001,0.002$, and 0.015 , respectively). Overall survival in the NAC-RT group was comparable to that in the control group, although patients with BR-PHC generally had a poorer prognosis than those with resectable PHC. Patients in the NAC-RT group without
\end{abstract}

Correspondence to: Dr Yoshiki Naito, Department of Diagnostic Pathology, Kurume University Hospital, 67 Asahimachi, Kurume, Fukuoka 830-0011, Japan

E-mail: nyoshiki@med.kurume-u.ac.jp

*Contributed equally

Key words: pancreas, pancreatic head cancer, neoadjuvant chemoradiotherapy, portal vein invasion, microvessel invasion portal vein invasion (PVI) had a significantly better prognosis than those with PVI in the control group $(\mathrm{P}=0.002)$. NAC-RT may be beneficial for patients with BR-PHC by inhibiting local invasion and metastasis as prognosis following resection could be equivalent to that of patients with conventional ductal adenocarcinoma.

\section{Introduction}

Pancreatic cancer (PC) is one of the most lethal malignant neoplasms and a major cause of cancer-related death in developed countries (1-3). Surgical resection has contributed to favorable prognosis, and progress in surgical techniques and perioperative care have reduced the rates of mortality and severe complications (4-6). However, the long-term survival rate has plateaued over the last three decades (7). Most patients present with advanced stage at initial diagnosis (8), and effective drugs are still under development because of the complexity of PC at the genomic, epigenetic, and metabolic levels (9-11). Particularly, patients with advanced stage pancreatic head cancer (PHC) can often only undergo non-curative operation, as the tumor cells tend to invade adjacent main vessels. However, chemotherapy and/or radiation therapy prior to operation, known as neoadjuvant chemoradiotherapy (NAC-RT), has been recently introduced as a treatment strategy, and has achieved several successful outcomes $(7,9,12-14)$.

Borderline resectable PHC (BR-PHC) is defined as a tumor of low resectability because it is accompanied by vascular invasion, especially portal venous and arterial involvement (15-17). The possibility of complete resection of BR-PHC depends on the efficacy of preoperative NAC-RT, i.e., stable disease or complete or partial response (9). Jang et al (14). reported that 
the 2-year prognosis of patients who received neoadjuvant treatment was significantly better than the prognosis of those receiving upfront surgery. There are several reasons for this, including early systemic treatment for undetected micrometastases, no residual tumor (R0) rate increment, and optimal selection of patients for surgery (14). Above all, R0 resection is closely linked to the regression of local vascular invasion, more specifically, invasion to the portal and superior mesenteric veins.

Japanese pathologists routinely make meticulous diagnoses using the Japanese Classification of Pancreatic Cancer (18), which requires individual evaluation of invasion of the bile duct, duodenum, anterior or posterior pancreatic tissue, portal venous system, arterial system, extrapancreatic nerve plexus and surgical margin. In contrast, these parameters are combined in the World Health Organization (WHO) classification, thus the diagnosis of T3 tumors remains only a rough estimate. Since PHC deserves careful attention, our approach of separate evaluation seems to be indispensable to specify important factors for the prognosis of PC.

This study compared the clinicopathological features of BR-PHC with NAC-RT and resectable PHC and tried to clarify the critical factors influencing the prognosis of PHC.

\section{Materials and methods}

Patient selection. This study was a retrospective cohort study using clinicopathological data from the Kurume University Hospital between 2009 and 2016. It was approved by the ethical committee of Kurume University (approved \# 17226). Twenty-nine patients with BR-PHC who received NAC-RT were reevaluated. Patients with unresectable PC (UR-PC) were excluded from the study. All patients received a combination of chemotherapy with gemcitabine (600 mg/m²/week) S-1 $\left(50 \mathrm{mg} / \mathrm{m}^{2} /\right.$ day) and radiotherapy (50.4 Gy). Approximately one month after conclusion of this neoadjuvant therapy, pancreaticoduodenectomy (PD) was performed under the conditions of no disease progression, metastasis, or contraindications to major abdominal surgery. Pre-treatment cytology under EUS-FNA or ERCP (19) and imaging findings were reviewed in all PHC patients with NAC-RT. Clinical follow-up data were available for overall survival (OS). A control group consisted of resectable 55 PHC patients who underwent PD during the same period.

Resected specimens (pancreas and surrounding tissue) were fixed with $10 \%$ buffered formalin; they were then totally sectioned (18 to 42 slides) and embedded in paraffin for microscopic examination. All slides were consecutively cut to 4-mm thickness, stained with hematoxylin and eosin, and evaluated by two pathologists (Y.N., M.T, M.N.). Histological diagnosis was performed based on the 2010 WHO classification, and, according to the Japanese Classification of Pancreatic Cancer (18); invasion to the bile duct, duodenum, serosal side of the anterior pancreatic tissue, retropancreatic tissue, portal venous system, arterial system, extrapancreatic nerve plexus and surgical margin were assessed separately. The extent of residual carcinoma in specimens of BR-PHC after NAC-RT was also evaluated; histological response was classified based on the residual rate of viable cancer cells in post-treatment surgical specimens (Table I) (18). In this study, arterial system invasion was not observed, but cases with portal venous system invasion were defined as local invasion. After HE staining, regions in which viable tumor cells remained were selected and measured as the tumor diameter. For R assessment, cases without exposed tumor cells on the surgically dissected surface were categorized as R0, and cases with exposed tumor cells were categorized as R1. D2-40 immunohistochemical staining (clone D2-40, Nichirei, Japan) for lymphovascular invasion (LVI) and Elastica van Gieson or Victoria blue H\&E staining for microvessel invasion (MVI) were prepared for accurate evaluation. Tumor cell invasion into lymph ducts comprised of D2-40 positive endothelial cells was categorized as LVI. Tumor cell invasion findings in veins with elastic fiber measuring more than half the diameter on EVG or Victoria blue H\&E staining were categorized as MVI.

Statistical analysis. Continuous variables were expressed as medians and ranges and categorical variables as numbers and percentages. Clinicopathological variables were compared using Wilcoxon rank sum, Chi-square, or Fisher exact tests. The survival function for OS was estimated using the Kaplan-Meier method. The log-rank test was used to compare differences in survival rates according to clinicopathological variables. All statistical analyses were performed using SAS version 9.4 (SAS Institute Inc., Cary, NC) and R version 3.4.4. All statistical tests were two-tailed, and P-values $<0.05$ was considered statistically significant.

\section{Results}

Histological assessment of the preoperative therapeutic effect of NAC-RT on BR-PHC. Representative morphopathological features of BR-PHC after NAC-RT are shown in Fig. 1. The post-therapeutic response of tumor cells was represented by clear cytoplasm, pyknosis, loss of nuclei, and indistinct cell borders. In some cases, mucin pools or xanthogranuloma-like features with coarse fibrosis were observed as the host tissue response. Interestingly, intraductal components corresponding to high grade pancreatic intraepithelial neoplasia (PanIN) remained in the pancreatic ducts (Fig. 2). Clinicopathological data of the BR-PHC with NAC-RT and control groups are shown in Table II. The NAC-RT group consisted of 16 men and 13 females and the median age was 66.0 (range 50-78) years. The median tumor size was 20 (range 0-43) mm. Upon comparison of the post therapy tumor stages (ypT0/T1/T2 vs. ypT3), ypT3 was predominant (9 and 23, respectively). For the one patient with pCR (ypT0) (Fig. 3), (20) the pretreatment computerized tomography showed a mass lesion in the pancreas head, and the pretreatment cytology diagnosis was adenocarcinoma. Six patients $(21.0 \%)$ with lymph node metastasis were classified with ypStage IIB disease. According to the WHO classification standards, 27 of the $29(93.1 \%)$ cases with viable tumors were well to moderately differentiated and $1(3.4 \%)$ was poorly differentiated. In one case, there was no viable cancer cells in any of the specimens (pCR) (20). R0 resection was achieved in $25(86 \%)$ patients. Pathological evaluation of local invasion among the BR-PHC with NAC-RT and the control groups is shown in Table III. Based on the Japanese Classification of Pancreatic Cancer protocol, the histological response to NAC-RT was classified as Grade 1a, 
Table I. Histological assessment of preoperative therapeutic effects.

A, Japanese classification of pancreatic cancer

\begin{tabular}{lll} 
Grade 1 & Poor or no response & Estimated residual rate $\geq 90 \%$ \\
& Grade 1a & $10 \% \leq$ estimated residual rate $<50 \%$ \\
Grade 2 & Moderate response & \\
Grade 3 & Marked response & \\
& Estimated residual rate $<10 \%$ & \\
Grade 4 & Complete response & \\
\hline
\end{tabular}

B, Evans grading system

Grade I $\quad<10 \%$ or no tumor cell destruction is evident

Grade II

$\mathrm{IIb}$

Grade III $<10 \%$ viable-appearing tumor cells are present

Grade IV No viable tumor cells are present
Destruction of $10-50 \%$ of tumor cells Destruction of $51-90 \%$ of tumor cells

C, CAP grading system

$\begin{array}{ll}\text { Grade } 0 & \text { Complete response } \\ \text { Grade } 1 & \text { Marked response } \\ \text { Grade } 2 & \text { Moderate response } \\ \text { Grade } 3 & \text { Poor or no response }\end{array}$

CAP, College of American Pathologists grading system.
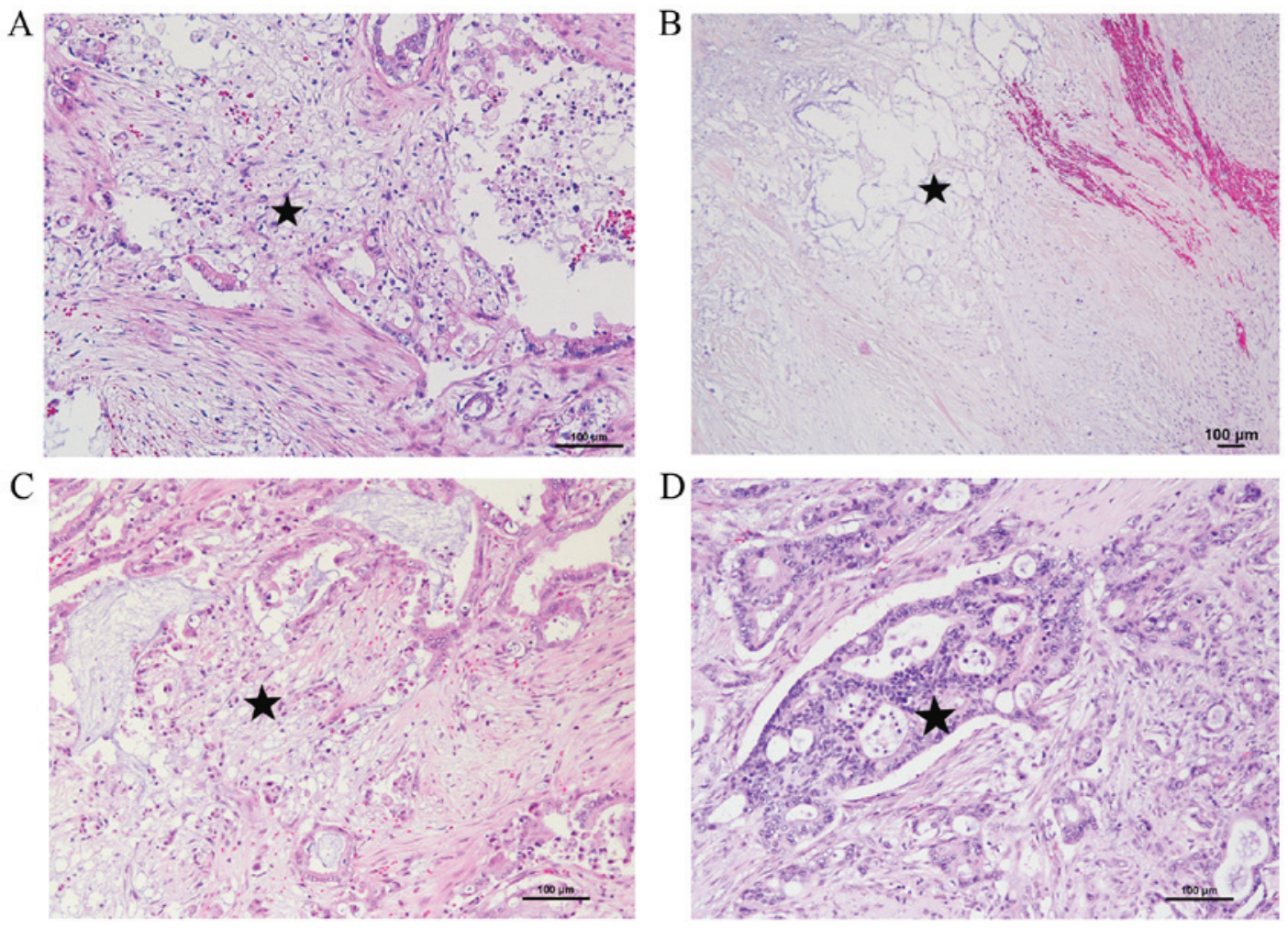

Figure 1. Histological findings of resected BR-PHC tissue after NAC-RT. (A) Degenerated cells (star) with clear cytoplasm, pyknosis, loss of nuclei, and indistinct cell borders (magnification, x100). (B) Cancer cells with mucin pools replaced by fibrosis (star) (magnification, x40). (C) Xanthogranuloma-like feature and coarse fibrosis (star) (magnification, x100). (D) Viable cancer cells without therapeutic response (star) (magnification, x400). BR-PHC, Borderline resectable pancreatic head cancer; NAC-RT, neoadjuvant chemoradiotherapy. 
Table II. Clinicopathological data of BR-PHC with NAC-RT and control groups.

\begin{tabular}{|c|c|c|c|c|c|c|}
\hline Characteristics & Categories & BR-PHC with NAC-RT & $(\%)$ & Control PHC & $(\%)$ & P-value \\
\hline No. of patients & & 29 & & 55 & & \\
\hline Age, y median (min-max) & & $66(50-78)$ & & $68(37-81)$ & & 0.281 \\
\hline \multirow[t]{2}{*}{ Sex } & Male & 16 & $(55.2)$ & 36 & $(65.5)$ & 0.356 \\
\hline & Female & 13 & $(44.8)$ & 19 & $(34.5)$ & \\
\hline \multirow[t]{2}{*}{ Operation } & PD & 19 & $(65.5)$ & 46 & $(83.6)$ & 0.098 \\
\hline & PD with PV & 10 & $(34.5)$ & 9 & $(16.4)$ & \\
\hline Tumor size (mm) median (min-max) & & $20(0-43)$ & & $28(0.8-85)$ & & 0.006 \\
\hline \multirow[t]{2}{*}{ Tumor stage $(\mathrm{T})$} & $\mathrm{T} 0 / 1 / \mathrm{pT} 2$ & 9 & $(31.0)$ & 8 & $(14.5)$ & 0.074 \\
\hline & T3 & 20 & $(69.0)$ & 47 & $(85.5)$ & \\
\hline \multirow[t]{2}{*}{ Regional LN } & No & 23 & (79.3) & 20 & $(36.4)$ & $<0.001$ \\
\hline & N1 & 6 & $(20.7)$ & 35 & $(63.6)$ & \\
\hline \multirow[t]{3}{*}{ Stage } & 0/IA/IB & 8 & $(27.6)$ & 5 & $(9.1)$ & $<0.001$ \\
\hline & IIA & 15 & $(51.7)$ & 15 & $(27.3)$ & \\
\hline & IIB & 6 & $(20.7)$ & 35 & $(63.6)$ & \\
\hline \multirow[t]{2}{*}{ Histolog $y^{a}$} & $\mathrm{G} 1 / 2$ & 27 & $(93.1)$ & 46 & $(83.6)$ & 0.153 \\
\hline & $\mathrm{G} 3 / 4$ & 1 & $(3.4)$ & 9 & $(16.4)$ & \\
\hline \multirow[t]{2}{*}{ LVI } & Present & 15 & $(51.7)$ & 46 & $(83.6)$ & 0.002 \\
\hline & Absent & 14 & $(48.3)$ & 9 & $(16.4)$ & \\
\hline \multirow[t]{2}{*}{ MVI } & Present & 18 & $(62.1)$ & 47 & $(85.5)$ & 0.015 \\
\hline & Absent & 11 & $(37.9)$ & 8 & $(14.5)$ & \\
\hline \multirow[t]{2}{*}{ NI } & Present & 22 & $(75.9)$ & 50 & $(90.9)$ & 0.098 \\
\hline & Absent & 7 & $(24.1)$ & 5 & $(9.1)$ & \\
\hline \multirow[t]{2}{*}{ Surgical margin (R) } & Present & 4 & $(13.8)$ & 6 & $(10.9)$ & 0.731 \\
\hline & Absent & 25 & $(86.2)$ & 49 & $(89.1)$ & \\
\hline
\end{tabular}

Data are presented as $\mathrm{n}(\%)$ unless otherwise indicated. BR-PHC, Borderline resectable pancreatic head cancer; NAC-RT, neoadjuvant chemoradiotherapy; PHC, pancreatic head cancer; PD, pancreaticoduodenectomy; LN, lymph nodes; LVI, lymphovascular invasion; MVI, microvascular invasion; NI, neural invasion. ${ }^{\mathrm{p}} \mathrm{pCR}$ case was excluded.
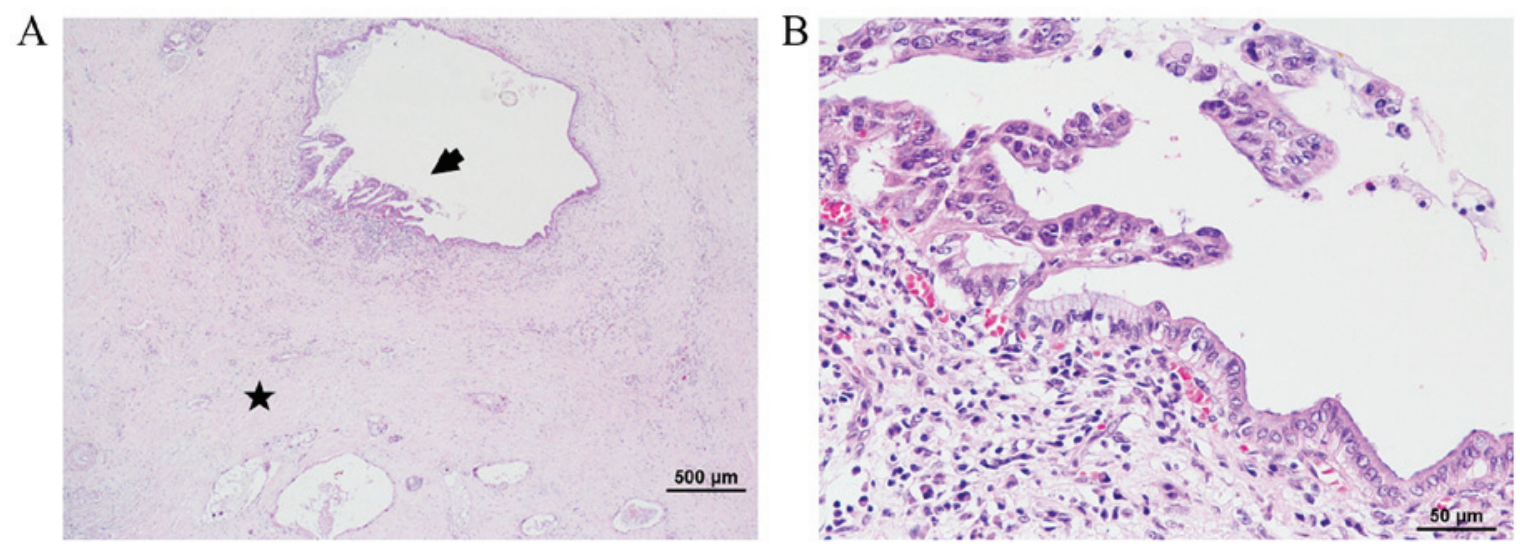

Figure 2. High grade PanIN in resected BR-PHC tissue after NAC-RT. (A) High grade PanIN within a large or medium pancreatic duct (star: Invasion areas, arrow: High grade PanIN) (magnification, x20). (B) Columnar epithelium showed low papillary growth and a budding structure (magnification, x200). PanIN, pancreatic intraepithelial neoplasia; BR-PHC, Borderline resectable pancreatic head cancer; NAC-RT, neoadjuvant chemoradiotherapy.

Grade 1b, Grade 2, Grade 3, or Grade 4. Grade 1b (55.0\%) was the most common, and only one case (4.0\%) was Grade 4 (this case achieved pCR) (Table IV). The Grade 4 case had no recurrence for 4 years.
Correlation of survival with histologic parameters of local invasion of the residual tumor. Comparison of $\mathrm{PHC}$ between the NAC-RT and control groups is shown in Table II. The median tumor size was significantly smaller in the NAC-RT 
Table III. Pathological evaluation of local invasion among BR-PHC with NAC-RT and control groups.

\begin{tabular}{|c|c|c|c|c|c|}
\hline & BR-PHC with NAC-RT $(n=29)$ & $\%$ & Control PHC $(n=55)$ & $\%$ & P-value \\
\hline \multicolumn{6}{|l|}{$\mathrm{CH}$} \\
\hline Present & 4 & $(13.8)$ & 32 & $(58.2)$ & \multirow[t]{2}{*}{$<0.001$} \\
\hline Absent & 25 & $(86.2)$ & 23 & $(41.8)$ & \\
\hline \multicolumn{6}{|l|}{ DU } \\
\hline Present & 13 & $(44.8)$ & 30 & $(54.5)$ & \multirow[t]{2}{*}{0.397} \\
\hline Absent & 16 & $(55.2)$ & 25 & $(45.5)$ & \\
\hline \multicolumn{6}{|l|}{$\mathrm{S}$} \\
\hline Present & 5 & $(17.2)$ & 15 & $(27.3)$ & \multirow[t]{2}{*}{0.305} \\
\hline Absent & 24 & $(82.8)$ & 40 & $(72.7)$ & \\
\hline \multicolumn{6}{|l|}{$\mathrm{RP}$} \\
\hline Present & 10 & $(34.5)$ & 31 & $(56.4)$ & \multirow[t]{2}{*}{0.057} \\
\hline Absent & 19 & $(65.5)$ & 24 & $(43.6)$ & \\
\hline \multicolumn{6}{|l|}{ PV } \\
\hline Present & 5 & $(17.2)$ & 4 & $(7.3)$ & \multirow[t]{2}{*}{0.264} \\
\hline Absent & 24 & $(82.8)$ & 51 & (92.7) & \\
\hline \multicolumn{6}{|l|}{ A } \\
\hline Present & 0 & $(0.0)$ & 0 & $(0.0)$ & \multirow[t]{2}{*}{-} \\
\hline Absent & 29 & $(100.0)$ & 55 & $(100.0)$ & \\
\hline \multicolumn{6}{|l|}{ PL } \\
\hline Present & 1 & $(3.4)$ & 5 & $(9.1)$ & \multirow[t]{2}{*}{0.659} \\
\hline Absent & 28 & (96.6) & 50 & (90.9) & \\
\hline \multicolumn{6}{|l|}{$\mathrm{OO}$} \\
\hline Present & 0 & $(0.0)$ & 0 & $(0.0)$ & \multirow[t]{2}{*}{-} \\
\hline Absent & 29 & $(100.0)$ & 55 & $(100.0)$ & \\
\hline
\end{tabular}

BR-PHC, Borderline resectable pancreatic head cancer; NAC-RT, neoadjuvant chemoradiotherapy; $\mathrm{CH}$, pathological bile duct invasion; DU, pathological Duodenal invasion; S, pathological serosal side of the anterior pancreatic tissue invasion; RP, pathological retropancreatic tissue invasion; PV, pathological portal venous system invasion; A, pathological arterial system invasion; PL, pathological extrapancreatic nerve plexus invasion; OO, pathological invasion of other organs.
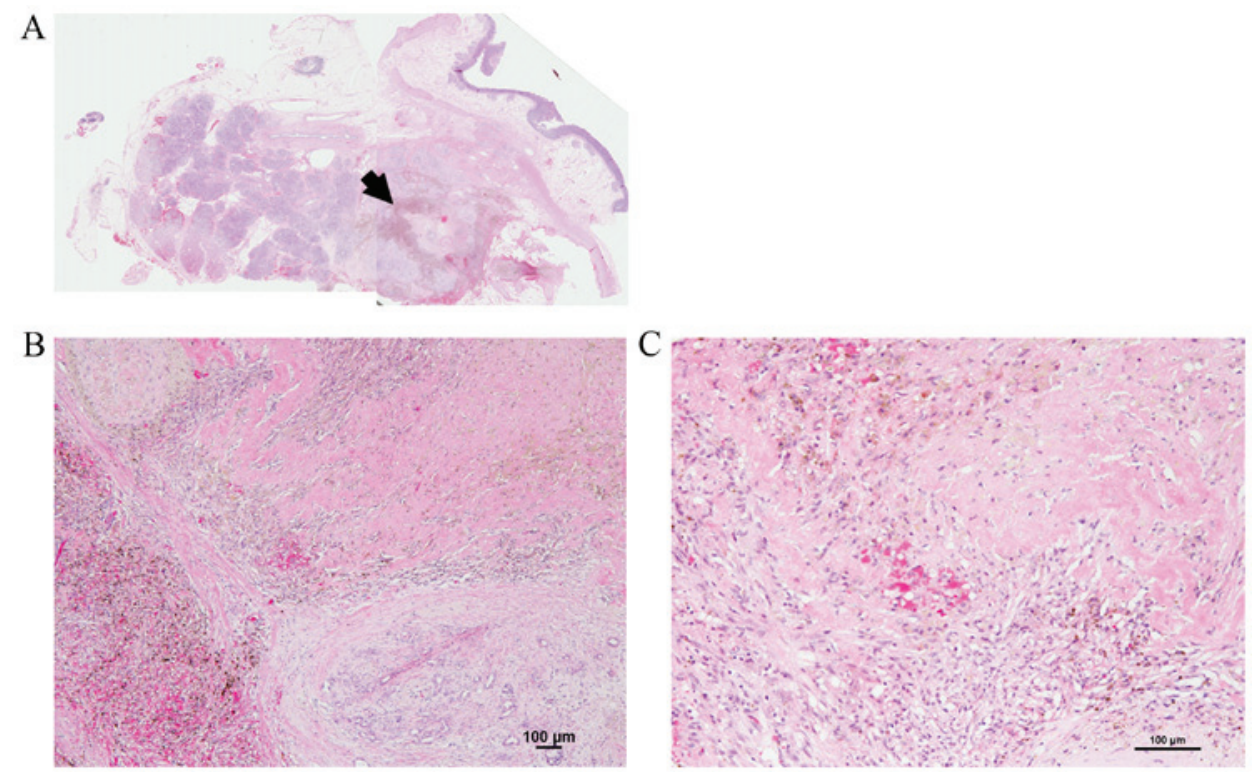

Figure 3. Grade 4 effect of NAC-RT on BR-PHC. (A) Macroscopic findings of the resected pancreatic head cancer showed white and brown colored lesion (arrow). (B and C) Histopathological examination revealed that the tumor cell have disappeared and carcinoma cells had been replaced by fibrosis and remarkable hemorrhage in the pancreatic parenchyma. (magnification, x40; x100). BR-PHC, Borderline resectable pancreatic head cancer; NAC-RT, neoadjuvant chemoradiotherapy. 
Table IV. Grading of histological response to neoadjuvant chemoradiotherapy in BR-PHC.

\begin{tabular}{lccr}
\hline CAP system & Evans classification & JPS classification & Patients $(\%)$ \\
\hline Grade 3 & Grade I & Grade $1 \mathrm{a}$ & $5(17.0)$ \\
& Grade IIa & Grade $1 \mathrm{~b}$ & $16(55.0)$ \\
Grade 2 & Grade IIb & Grade 2 & $7(24.0)$ \\
Grade 1 & Grade III & Grade 3 & $0(0.0)$ \\
Grade 0 & Grade IV & Grade 4 & $(4.0)$ \\
\hline
\end{tabular}

BR-PHC, Borderline resectable pancreatic head cancer; JPS, Japanese Pancreas Society; CAP, College of American Pathologists grading system.
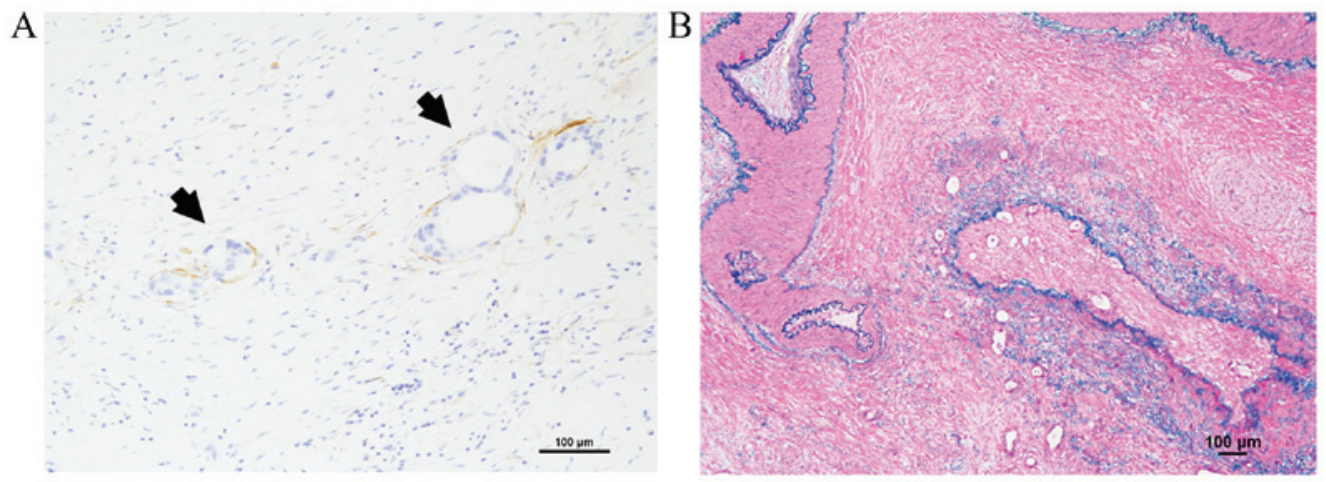

Figure 4. LVI and MVI in resected BR-PHC tissues after NAC-RT. (A) Tumor cell invasion into lymph ducts comprised of D2-40 positive endothelial cells was categorized as LVI (arrows). (B) Tumor cell invasion findings in veins with elastic fiber measuring more than half the diameter on Victoria blue H\&E staining were categorized as MVI. (A, D2-40 magnification, x100; B, Victoria blue H\&E magnification, x40). BR-PHC, Borderline resectable pancreatic head cancer; LVI, lymphovascular invasion; MVI, microvessel invasion.
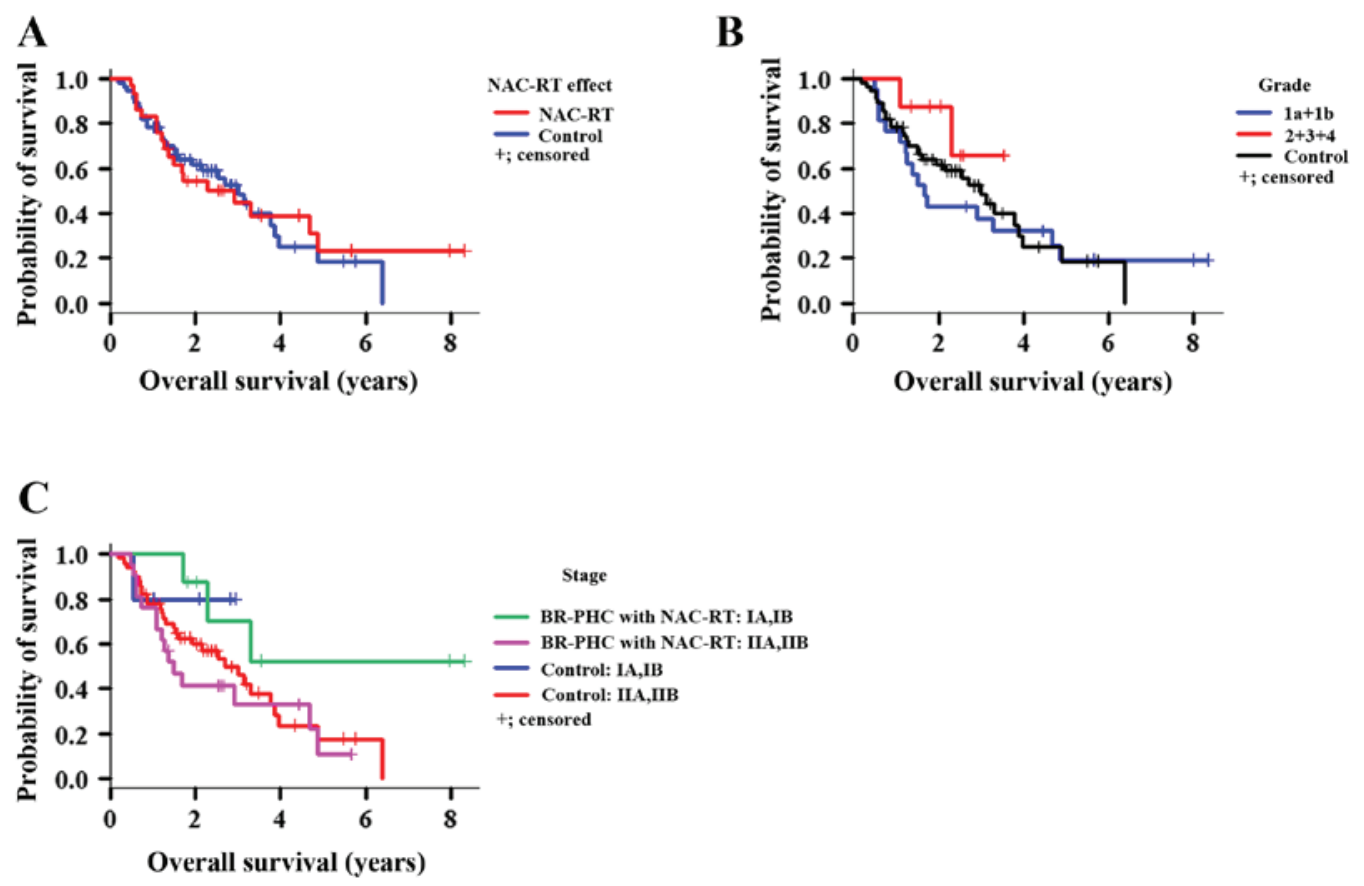

Figure 5. (A) Overall survival by NAC-RT, (B) NAC-RT effect, and (C) Stage after NAC-RT. (A) P=0.831, (B) P=0.470, (C) P=0.167 (log rank test).

group $(\mathrm{P}=0.006)$. Lymph node metastases were significantly less common in the NAC-RT group than in the control group $(\mathrm{P}<0.001)$. Moreover, the NAC-RT group had significantly lower rates of LVI $(51.7 \%)$ and MVI (62.1\%) than the control group (MVI: $\mathrm{P}=0.015$, LVI: $\mathrm{P}=0.02$; Fig. 4). OS was similar between the BR-PHC with NAC-RT and control 


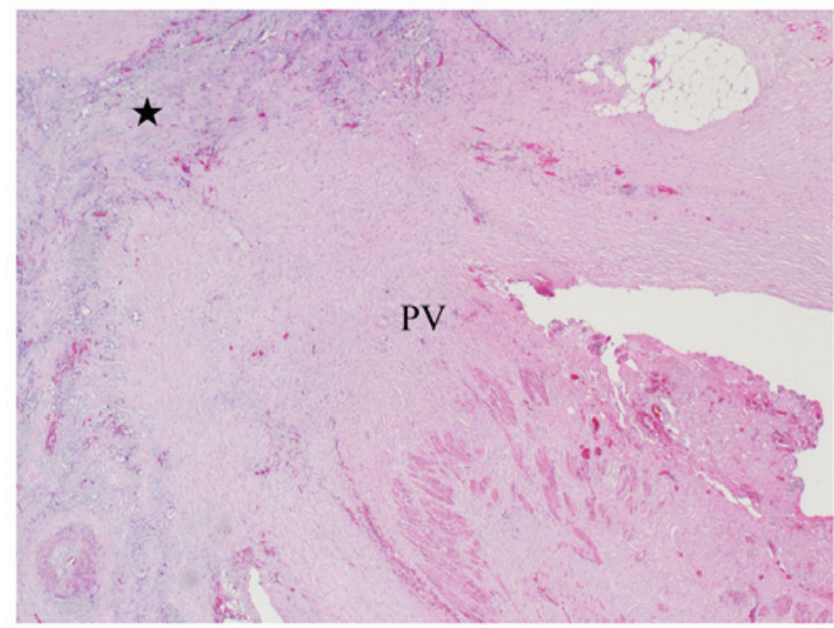

Figure 6. Portal vein invasion in resected BR-PHC tissues after NAC-RT. Post-treatment scar with xanthogranuloma-like features and coarse fibrosis (star); there were no cancer cells in the portal vein system (PV). (magnification, x200) BR-PHC, Borderline resectable pancreatic head cancer; NAC-RT, neoadjuvant chemoradiotherapy.

groups $(\mathrm{P}=0.831$; Fig. 5A). Additionally, there were no significant differences in OS between the two groups based on grade (Fig. 5B, $\mathrm{P}=0.470$ ) or stage (Fig. 5C, $\mathrm{P}=0.167$ ). However, patients in the NAC-RT group with portal vein invasion (PVI) (Fig. 6), MVI, and surgical margin factors had significantly shorter OS than the corresponding patients in the control group $(\mathrm{P}=0.002, \mathrm{P}=0.011, \mathrm{P}=0.043$, respectively; Fig. 7). Conversely, the BR-PHC with NAC-RT patients without PVI had a significantly better prognosis than patients in the control group with PVI $(\mathrm{P}=0.002)$.

\section{Discussion}

We expected that BR-PHC patients who underwent NAC-RT would have shorter OS than resectable PHC patients, but we found no differences in survival between the two groups. There are several potential reasons for this, including early systemic treatment for undetected micrometastases via LVI and MVI, increases in the R0 resection rate as a result of downsizing the primary tumor and inhibiting local invasion, and optimal selection of patients for surgery. In particular, patients in the NAC-RT group without PVI had significantly better prognosis than patients in the control group with PVI in this study. In this comparison, patients with resectable pancreatic cancer with $\mathrm{PVI}$, in other words histologic BR-PHC, had better prognosis than PHC patients with resected PVI with NAC-RT. Despite the small case-number limitation, PVI resection with NAC-RT was considered to have important implications. Although there were a limited number of pCR cases, we observed that the majority of cases had some response to NAC-RT, which inhibited local invasion and good OS.

In general, PHC patients are diagnosed with locally advanced cancer or metastasis, and many cases are diagnosed as UR-PC at admission. Anatomical relations between the pancreatic head and surrounding tissue, such as the bile duct, major vessels, and duodenum, contribute to the high frequency of extrapancreatic invasion. Among such advanced PHC cases, our data showed that PVI and surgical margins had an impact
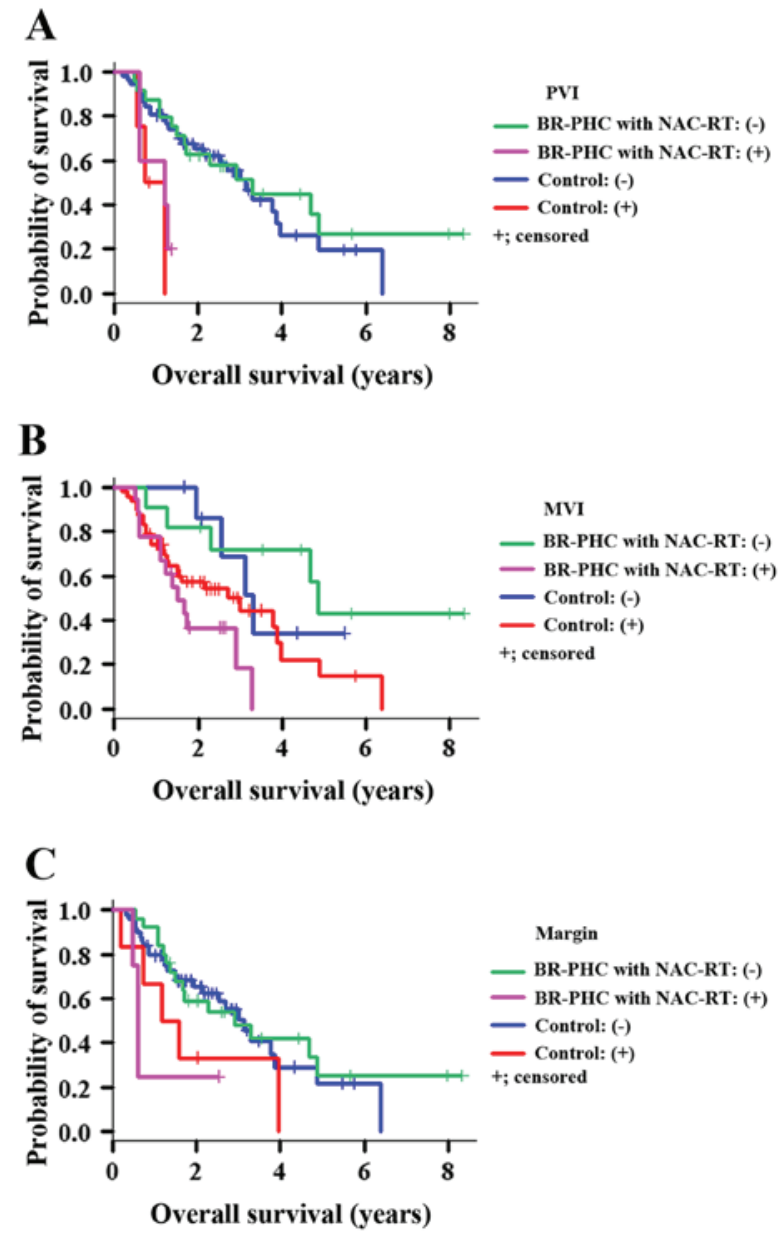

Figure 7. Overall survival by portal vein invasion (A) microvessel invasion, (B) and surgical margin (C). (A) $\mathrm{P}=0.002$, (B) $\mathrm{P}=0.011$, (C) $\mathrm{P}=0.043$ (log rank test).

on survival outcomes. Previous reports have demonstrated that adopting neoadjuvant treatment potentially increases R0 resection rates $(21,22)$. There are competing ideas as to the effect of PVI on survival. One stresses the importance of portal vein resection for PHC with PVI. The other concludes that portal vein resection has no impact on survival duration, and survival in patients who under portal vein resection does not differ from those who undergo standard PD (23).

The prognoses of BR-PHC patients who underwent NAC-RT were unfavorable by preoperative assessment, but improved to be comparable to that of resectable PHC patients, provided that PVIs were dissolved. Most PHCs show a high incidence of peritoneal dissemination or widespread metastasis, such as to the liver and lung (24). These conditions are strongly linked to hematogenous and lymphatic micrometastasis, which are regarded as prognostic factors in PC $(25,26)$. In this study, the NAC-RT group had significantly lower rates of lymph node metastasis, LVI, and MVI than the control group. Moreover, PVI turned out to be a crucial factor affecting OS. We predict that NAC-RT behaves as a protective measure in advanced PC to stem further progression of the disease. However, the fact that the OS of the NAC-RT group did not exceed that of the control group indicates that other factors, not only control or inhibition of LVI and MVI, should be taken into consideration to improve prognosis. 
In the present study, NAC-RT was expected to provide good local control and to decrease MVI and LVI in the BR-PHC microenvironment. However, remnants of high grade PanIN within the pancreatic ducts were frequently observed. This may indicate that, compared to invasive carcinoma, PanINs may be resistant to NAC-RT, or NAC-RT has only a limited effect. High grade PanINs often coexist with PC and cause high intraductal spread and shortens the survival of PC patients $(27,28)$. Careful follow-up will be needed in order to detect local recurrence or metastasis to other organs associated with high grade PanINs at an early point.

Histological features of residual carcinoma in post-therapy resection specimens has been shown to correlate with the prognosis of patients with PC and several gastrointestinal cancers (29-32). In this study, the post-therapeutic response of tumor cells was represented by clear cytoplasm, pyknosis, loss of nuclei, and indistinct cell borders. Additionally, mucin pools or xanthogranuloma-like features with coarse fibrosis were observed as the host tissue response. However, the histology of the preoperative therapeutic effect of BR-PHC was non-significantly correlated with OS in patients who received NAC-RT in this study. Moreover, as seen in Fig. 5B, survival curves (Grades 1a and 1b vs. Grades 2, 3, and 4) did not diverge until 8 years after surgery, regardless of control or inhibition of PVI, LVI, and MVI. Several studies have reported that chemotherapy such as FOLFIRINOX and gemcitabine combined with protein-bound paclitaxel (nab-paclitaxel) regimens are widely used due to the relatively high response rate (33-36). In our study, all patients received a combination of chemotherapy with gemcitabine or S-1. Therefore, future studies may need to identify more effective systemic treatments that control local disease and reduce systemic metastasis after treatment.

In summary, NAC-RT could improve the prognosis of BR-PHC patients, such that they have a prognosis similar to that of patients with resectable PHC, if it successfully controls or reduces local progression such as lymph node metastasis, LVI, and MVI. Furthermore, the dissolution of PVI and, although it was rare, complete response by NAC-RT led BR-PHC patients to have a better prognosis than resectable PHC patients.

\section{Acknowledgements}

Not applicable.

\section{Funding}

The present study was supported by the grant of the 2015 Clinical Research Promotion Foundation (No. 9).

\section{Availability of data and materials}

The datasets used and/or analyzed during the present study are available from the corresponding author on reasonable request.

\section{Authors' contributions}

YN, HI, ES, KS, HY and JA designed the study and drafted the manuscript. YN and ES performed the statistical analysis. YN, HI, YO, KT, RK, TH, MF, TU, YI, EO and KO. Collected the clinical data. YT and HA performed immunohistochemistry.
YN, MT, YM, MN, RK and HK performed pathological analysis.

\section{Ethics approval and consent to participate}

This retrospective study was approved by the ethical committee of Kurume University (approval no. 17226), and the requirement for informed consent was waived.

\section{Patient consent for publication}

Not applicable.

\section{Competing interests}

The authors declare that they have no competing interests.

\section{References}

1. Jemal A, Siegel R, Xu J and Ward E: Cancer statistics, 2010. CA Cancer J Clin 60: 277-300, 2010.

2. Egawa S, Toma H, Ohigashi H, Okusaka T, Nakao A, Hatori T, Maguchi H, Yanagisawa A and Tanaka M: Japan pancreatic cancer registry; 30th year anniversary: Japan pancreas society. Pancreas 41: 985-992, 2012.

3. Matsuno S, Egawa S, Fukuyama S, Motoi F, Sunamura M, Isaji S, Imaizumi T, Okada S, Kato H, Suda K, et al: Pancreatic cancer registry in Japan: 20 years of experience. Pancreas 28: 219-230, 2004.

4. Winter JM, Cameron JL, Campbell KA, Arnold MA, Chang DC, Coleman J, Hodgin MB, Sauter PK, Hruban RH, Riall TS, et al: 1423 pancreaticoduodenectomies for pancreatic cancer: A single-institution experience. J Gastrointest Surg 10: 1199-1210; discussion 1210-1191, 2006.

5. Grobmyer SR, Pieracci FM, Allen PJ, Brennan MF and Jaques DP: Defining morbidity after pancreaticoduodenectomy: Use of a prospective complication grading system. J Am Coll Surg 204: 356-364, 2007.

6. Kimura H, Ohtsuka T, Matsunaga T, Watanabe Y, Tamura K, Ideno N, Aso T, Miyazaki T, Osoegawa T, Aishima S, et al: Predictors and diagnostic strategies for early-stage pancreatic ductal adenocarcinoma: A retrospective study. Pancreas 44: 1148-1154, 2015.

7. Serrano PE, Cleary SP, Dhani N, Kim PT, Greig PD, Leung K, Moulton CA, Gallinger S and Wei AC: Improved long-term outcomes after resection of pancreatic adenocarcinoma: A comparison between two time periods. Ann Surg Oncol 22: 1160-1167, 2015.

8. Garcea G, Dennison AR, Pattenden CJ, Neal CP, Sutton CD and Berry DP: Survival following curative resection for pancreatic ductal adenocarcinoma. A systematic review of the literature. JOP 9: 99-132, 2008.

9. Neoptolemos JP, Kleeff J, Michl P, Costello E, Greenhalf W and Palmer DH: Therapeutic developments in pancreatic cancer: Current and future perspectives. Nat Rev Gastroenterol Hepatol 15: 333-348, 2018.

10. Kleeff J, Korc M, Apte M, La Vecchia C, Johnson CD, Biankin AV, Neale RE, Tempero M, Tuveson DA, Hruban RH and Neoptolemos JP: Pancreatic cancer. Nat Rev Dis Primers 2: $16022,2016$.

11. Vincent A, Herman J, Schulick R, Hruban RH and Goggins M: Pancreatic cancer. Lancet 378: 607-620, 2011.

12. Xu Y, Guo X, Fan Y, Wang D, Wu W, Wu L, Liu T, Xu B, Feng Y, Wang Y, et al: Efficacy and safety comparison of nabpaclitaxel plus S-1 and gemcitabine plus S-1 as first-line chemotherapy for metastatic pancreatic cancer. Jpn J Clin Oncol 48: 535-541, 2018.

13. Sherman WH, Hecht E, Leung D and Chu K: Predictors of response and survival in locally advanced adenocarcinoma of the pancreas following neoadjuvant GTX with or without radiation therapy. Oncologist 23: 4-e10, 2018.

14. Jang JY, Han Y, Lee H, Kim SW, Kwon W, Lee KH, Oh DY, Chie EK, Lee JM, Heo JS, et al: Oncological benefits of neoadjuvant chemoradiation with gemcitabine versus upfront surgery in patients with borderline resectable pancreatic cancer: A prospective, randomized, open-label, multicenter phase 2/3 trial. Ann Surg 268: 215-222, 2018. 
15. Yamada S, Fujii T, Sugimoto H, Nomoto S, Takeda S, Kodera Y and Nakao A: Aggressive surgery for borderline resectable pancreatic cancer: Evaluation of national comprehensive cancer network guidelines. Pancreas 42: 1004-1010, 2013.

16. Isaji S, Mizuno S, Windsor JA, Bassi C, Fernandez-Del Castillo C, Hackert T, Hayasaki A, Katz MHG, Kim SW, Kishiwada M, et al: International consensus on definition and criteria of borderline resectable pancreatic ductal adenocarcinoma 2017. Pancreatology 18: 2-11, 2018.

17. Ishikawa O, Ohigashi H, Imaoka S, Furukawa H, Sasaki Y, Fujita M, Kuroda C and Iwanaga T: Preoperative indications for extended pancreatectomy for locally advanced pancreas cancer involving the portal vein. Ann Surg 215: 231-236, 1992.

18. Uchida K and Masugi Y: Histological assessment of therapeutic response. In: Classification of Pancreatic Carcinoma: Japan Pancreas Society. Isaji S (ed.). Kanehara \& Co., Ltd., Tokyo, pp117-122, 2017.

19. Ushijima T, Okabe Y, Ishida Y, Sugiyama G, Sasaki Y, Kuraoka K, Yasumoto M, Taira T, Naito Y, Nakayama M, et al: Evaluation of endoscopic cytological diagnosis of unresectable pancreatic cancer prior to and after the introduction of endoscopic ultrasound-guided fine-needle aspiration. Mol Clin Oncol 2: 599-603, 2014.

20. Nakama Y, Kawahara R, Nomura Y, Muroya D, Arai S Ishikawa $\mathrm{H}$, Yasunaga $\mathrm{M}$, Horiuchi $\mathrm{H}$, Akagi $\mathrm{Y}$, Tanaka $\mathrm{H}$, et al A case of pancreatic head cancer showing pathological complete response to neoadjuvant chemoradiation therapy. Gan To Kagaku Ryoho 42: 2376-2378, 2015 (In Japanese).

21. Ravikumar R, Sabin C, Abu Hilal M, Bramhall S, White S, Wigmore S, Imber CJ and Fusai G; UK Vascular Resection in Pancreatic Cancer Study Group: Portal vein resection in borderline resectable pancreatic cancer: A United Kingdom multicenter study. J Am Coll Surg 218: 401-411, 2014.

22. Yekebas EF, Bogoevski D, Cataldegirmen G, Kunze C, Marx A Vashist YK, Schurr PG, Liebl L, Thieltges S, Gawad KA, et al: En bloc vascular resection for locally advanced pancreatic malignancies infiltrating major blood vessels: Perioperative outcome and long-term survival in 136 patients. Ann Surg 247: 300-309, 2008.

23. Tseng JF, Raut CP, Lee JE, Pisters PW, Vauthey JN, Abdalla EK, Gomez HF, Sun CC, Crane CH, Wolff RA and Evans DB: Pancreaticoduodenectomy with vascular resection: Margin status and survival duration. J Gastrointest Surg 8: 935-949; discussion 949-950, 2004.

24. Iacobuzio-Donahue CA, Fu B, Yachida S, Luo M, Abe H, Henderson CM, Vilardell F, Wang Z, Keller JW, Banerjee P, et al: DPC4 gene status of the primary carcinoma correlates with patterns of failure in patients with pancreatic cancer. J Clin Oncol 27: 1806-1813, 2009.

25. Hamada Y and Nakayama Y: Aggressive venous invasion in the area of carcinoma correlates with liver metastasis as an index of metastasis for invasive ductal carcinoma of the pancreas Pancreatology 17: 951-955, 2017.

26. Nagakawa Y, Aoki T, Kasuya K, Tsuchida A and Koyanagi Y: Histologic features of venous invasion, expression of vascular endothelial growth factor and matrix metalloproteinase- 2 and matrix metalloproteinase-9, and the relation with liver metastasis in pancreatic cancer. Pancreas 24: 169-178, 2002.

27. Naito Y, Suda K, Nobukawa B, Kinoshita H and Kojiro M: Histopathological study of invasive ductal carcinoma (IDC) of the pancreas without associated cancerous occlusion of the main pancreatic duct. J Hepatobiliary Pancreat Surg 13: 556-561, 2006.
28. Yamasaki S, Suda K, Nobukawa B and Sonoue H: Intraductal spread of pancreatic cancer. Clinicopathologic study of 54 pancreatectomized patients. Pancreatology 2: 407-412, 2002.

29. Chatterjee D, Katz MH, Rashid A, Varadhachary GR, Wolff RA, Wang H, Lee JE, Pisters PW, Vauthey JN, Crane C, et al: Histologic grading of the extent of residual carcinoma following neoadjuvant chemoradiation in pancreatic ductal adenocarcinoma: A predictor for patient outcome. Cancer 118: 3182-3190, 2012.

30. Ajani JA, Mansfield PF, Crane $\mathrm{CH}$, Wu TT, Lunagomez S, Lynch PM, Janjan N, Feig B, Faust J, Yao JC, et al: Paclitaxel-based chemoradiotherapy in localized gastric carcinoma: Degree of pathologic response and not clinical parameters dictated patient outcome. J Clin Oncol 23: 1237-1244, 2005.

31. Wu TT, Chirieac LR, Abraham SC, Krasinskas AM, Wang H, Rashid A, Correa AM, Hofstetter WL, Ajani JA and Swisher SG: Excellent interobserver agreement on grading the extent of residual carcinoma after preoperative chemoradiation in esophageal and esophagogastric junction carcinoma: A reliable predictor for patient outcome. Am J Surg Pathol 31: 58-64, 2007.

32. Ryan R, Gibbons D, Hyland JM, Treanor D, White A, Mulcahy HE, O'Donoghue DP, Moriarty M, Fennelly D and Sheahan K: Pathological response following long-course neoadjuvant chemoradiotherapy for locally advanced rectal cancer. Histopathology 47: 141-146, 2005.

33. Katz MH, Shi Q, Ahmad SA, Herman JM, Marsh Rde W, Collisson E, Schwartz L, Frankel W, Martin R, Conway W, et al: Preoperative modified FOLFIRINOX treatment followed by capecitabine-based chemoradiation for borderline resectable pancreatic cancer: Alliance for clinical trials in oncology trial A021101. JAMA Surg 151: e161137, 2016.

34. Okada KI, Hirono S, Kawai M, Miyazawa M, Shimizu A, Kitahata Y, Ueno M, Hayami S and Yamaue H: Phase I study of nab-paclitaxel plus gemcitabine as neoadjuvant therapy for borderline resectable pancreatic cancer. Anticancer Res 37 : 853-858, 2017.

35. Okada KI, Shimokawa T, Hirono S, Kawai M, Sho M, Satoi S, Matsumoto I, Eguchi H, Murakami Y, Yamada S, et al: Effect of neoadjuvant nab-paclitaxel plus gemcitabine therapy on overall survival in patients with borderline resectable pancreatic cancer: A prospective multicenter phase II trial (NAC-GA Trial). Oncology 93: 343-346, 2017.

36. Von Hoff DD, Ramanathan RK, Borad MJ, Laheru DA, Smith LS, Wood TE, Korn RL, Desai N, Trieu V, Iglesias JL, et al: Gemcitabine plus nab-paclitaxel is an active regimen in patients with advanced pancreatic cancer: A phase I/II trial. J Clin Oncol 29: 4548-4554, 2011

This work is licensed under a Creative Commons Attribution-NonCommercial-NoDerivatives 4.0 International (CC BY-NC-ND 4.0) License. 